\title{
The Influence of Educational Technology in Improving the Performance of Students in Chemistry
}

\author{
F. Dampil, Member, IACSIT
}

\begin{abstract}
This paper determines the influence of educational technology with regards to the performance of students in chemistry. The e-connect technology of Mc Graw Hill in their technology bundled textbook are used to compare the result from the non-bundled technology. Three long exams are measured to determine the influence of educational technology. The average mean of the long exams and the percentage of passers are considered to determine the effect of this tool in the performance of the students. Data were collected and computed and found out that the use of online technology significantly affect the performance of students in chemistry.
\end{abstract}

Index Terms-Online learning, educational technology, chemistry, students' performance.

\section{INTRODUCTION}

There are different ways on how to enhance the performance of a students These are: 1). the face to face interaction where the student can directly ask question. 2). The use of computer aided instruction in which the teacher prepares a module for easy understanding of a teacher and 3). the use of on line learning or the use of educational technology. Currently, the use of educational technology is given more emphasis in this study. This is the newest interventions used by most academicians. The educational technology tool which will be used is the E-Connect.

\section{A. What Is e-Connect?}

E-connect gives immediate feedback, unlimited practice, lecture capture for studetns. It has media rich e- books. It has also a learnSmart's game-like interface which helps make learning fun while students compete against his classmates and students around the nation. LearnSmart ${ }^{\mathrm{TM}}$ is an intelligent learning system that answers the the knowledge gaps. LearnSmart then provides an individualized learning path, so one can spend less time reviewing areas that one already knows and more time in areas that doesn't [1]. The econnect homepage is shown below. In the homepage one can easily browse the importance of e-connect in learning. It has a guide for users and for the subject you want to explore. One needs to sign in to experience the beauty of e-connect [2].

Students nowadays are far different from students before. The use of technology are very easy with the GenerationY. Generation Y are the people born between the 1980's and the

Manuscript received May 24, 2014; revised July 30, 2014. The presentation and publication of this paper was supported in full by the Malayan Colleges Laguna, Pulo Diezmo Road, Pulo, Cabuyao Laguna 4025, Philippines.

F. G. Dampil is with the Malayan Colleges Laguna, Philippines (e-mail: fgdampil@mcl.edu.ph,fe_dampil@yahoo.com). year 2000, and these individuals are sometimes referred to as Gen Y, the Millennial Generation, or simply Millennials. They are next to generation $\mathrm{X}$. Gen $\mathrm{Y}$ are molded by technology that occurred through their youth. They are equipped with the latest technology, online and connected $24 / 7,365$ days a year. With this kind of students the learning through computer is an easy one [3] as shown in Fig. 1.

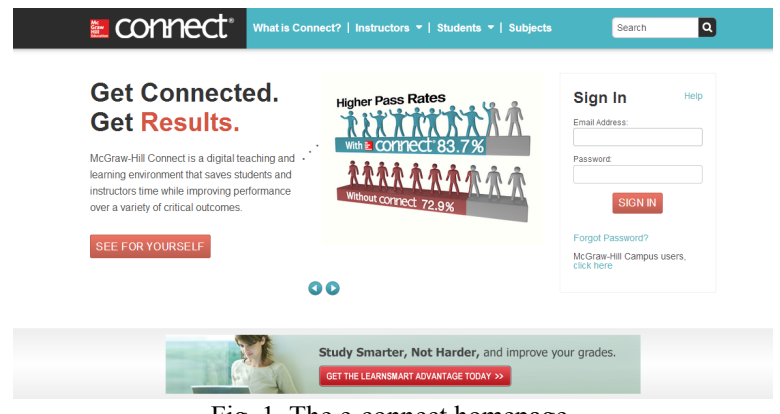

Fig. 1. The e-connect homepage.

For students' readiness in online technology and technology access it showed that $85.42 \%$ of students have technology access (own or have an access to a computer), internet connection which is $84.97 \%$, and tools is $92.11 \%$. Technology skills are also considered. The skills of the students showed $95.76 \%$, computer literacy is $88.35 \%$, and basic internet skills which is $86.51 \%$. Computer and internet access should be provided for them whenever they are in school to easily access their online courses, a training and resource materials can also be prepared for them so that they can improved on their internet skills and literacy on software application specifically on how to use the learning management system being used by MCL [4].

"A review of the literature shows that students' learning outcomes online are likely to be better when their actual learning environment closely matches their preferred or ideal learning environment. An online learning survey was administered to the students towards the end of their two-year course and the Wilcoxon signed rank test used to measure the difference between the student's actual and preferred experiences with the online activities that used constructivist theories. Findings - The findings showed that the activities provided by Moodle do foster a constructivist approach to learning and can provide students with the types of learning experiences they desire. However, their effectiveness is to a large extent dependent on the teacher's role in designing and directing the online learning experience. This is significant because it implies that for an online learning environment to be successful, a strong pedagogical strategy that emphasizes a constructivist approach needs to be consistently emphasized and practiced; having the technology tools available does not guarantee this" [5]. "In order for 21(st) 
century distance learning opportunities to continue to flourish and allow more consumers immediate availability to convenient and affordable education, immediate access to affordable broadband must continue to grow," said Dr. John G. Flores, Executive Director of the USDLA. "Online learning via the web, videoconferencing or satellite is keeping students engaged and in school, especially at-risk youth who are able to overcome educational obstacles because of the flexible and exciting nature of distance learning [6]. Students and lifelong learners has created one solution to the problem of making print and electronic materials available for the distance learner. The Florida Public Postsecondary Distance Learning Institute and the Florida Distance Learning Library Initiative are discussed [7].

\section{PROCESS}

There were four sections of chemistry students who were considered in this study. Two sections underwent the e-connect technology and 2 sections were considered under regular class discussion without the e-connect. Only one teacher handled the four sections. After giving them an exam, scores were collected and treated. The average mean and the number of passers were determined. Average mean is the sum of the grades being considered over the total number of entries. The percentage of passers is the total number of students who passed the course over the total number of students who took the course times 100. The following formula is given below.

$$
A=\frac{T}{n}
$$

where:

$A$ is the average mean

$T$ is sum of the grades being considered $n$ is the total number of entries

$$
\% P=\frac{N}{n} \times 100
$$

where:

$P$ is the percentage of passers

$N$ is the total number of students who passed the course $N$ is the total number of students who took the course

\section{RESULTS}

\section{A. Long Exam Results}

The average mean for long exam 1, 2 and 3 which $A_{1}, A_{2}$ and $A_{3}$ without e-connect is:

$$
\begin{gathered}
A=\frac{T}{n} \\
A_{1}=\frac{3397}{57}=59.59
\end{gathered}
$$

$$
\begin{aligned}
& A_{2}=\frac{3419}{57}=59.98 \\
& A_{3}=\frac{2857}{57}=50.12
\end{aligned}
$$

The average mean for long exam 1, 2 and 3 which $A_{1}, A_{2}$ and $A_{3}$ with e-connect is:

$$
\begin{gathered}
A=\frac{T}{n} \\
A_{1}=\frac{4289}{64}=67.01 \\
A_{2}=\frac{4268}{64}=66.69 \\
A_{3}=\frac{4062}{64}=63.47
\end{gathered}
$$

For the average mean of the long exam1, 2, and 3 of the students there is an increase of $7.42 \%, 6.71 \%$ and $13.35 \%$ respectively. This implies that the use of e-connect intervention caused the increase in the average mean (see Fig. 2 to Fig. 5).

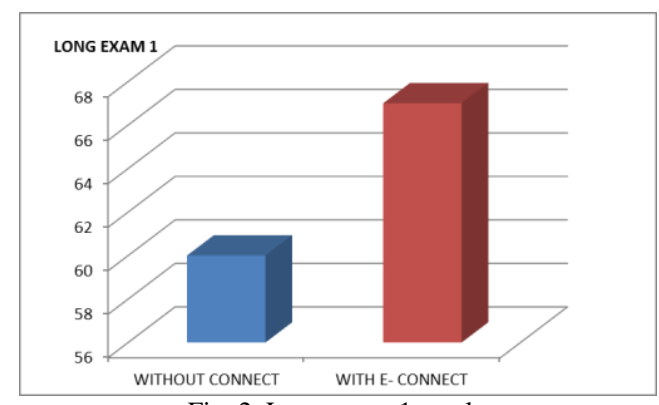

Fig. 2. Long exam 1 result.

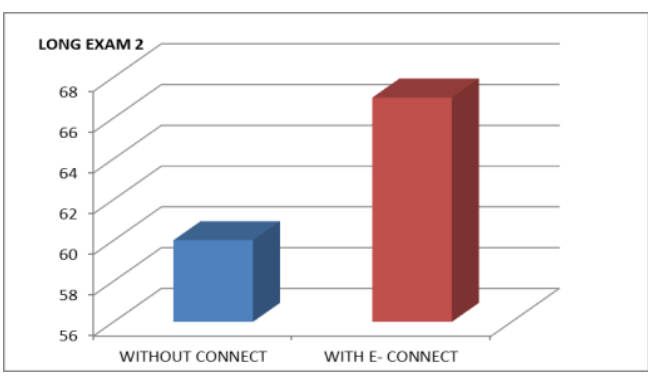

Fig. 3. Long exam 2 result.

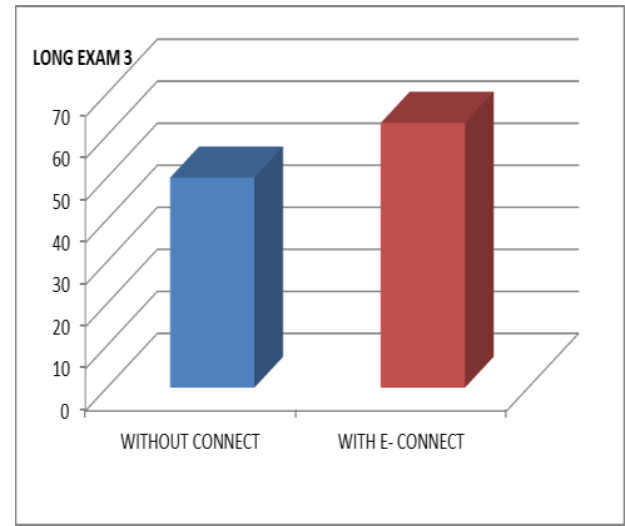

Fig. 4. Long exam 3 result. 


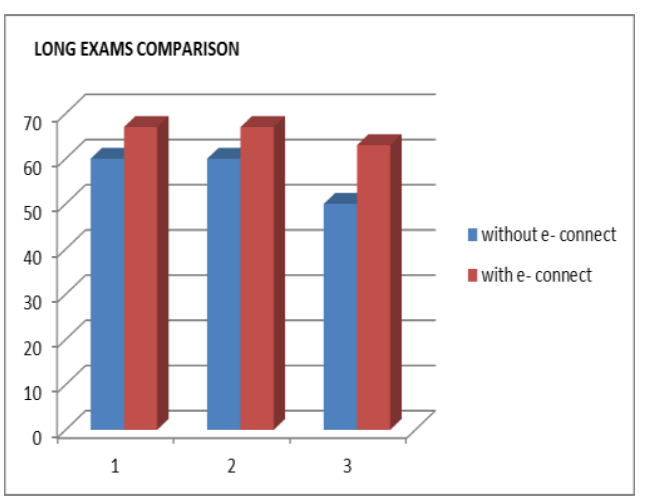

Fig. 5. Long exam comparison.

\section{B. Percentage of Passers}

The calculation for the percentage of passers for chemistry course for long exam 1,2 and 3 without the e-connect is given by $P_{1}, P_{2}, P_{3}$

$$
\begin{aligned}
& \% P=\frac{N}{n} \times 100 \\
& \% P_{1}=\frac{36}{57} \times 100=63.15 \\
& \% P_{2}=\frac{37}{57} \times 100=64.91 \\
& \% P_{3}=\frac{22}{57} \times 100=38.6
\end{aligned}
$$

The calculation for the percentage of passers for chemistry course for long exam 1, 2 and 3 with the e-connect is given by $P_{1}, P_{2}, P_{3}$

$$
\begin{aligned}
& \% P=\frac{N}{n} \times 100 \\
& \% P_{1}=\frac{46}{64} \times 100=71.88 \\
& \% P_{2}=\frac{49}{64} \times 100=76.56 \\
& \% P_{3}=\frac{44}{64} \times 100=68.75
\end{aligned}
$$

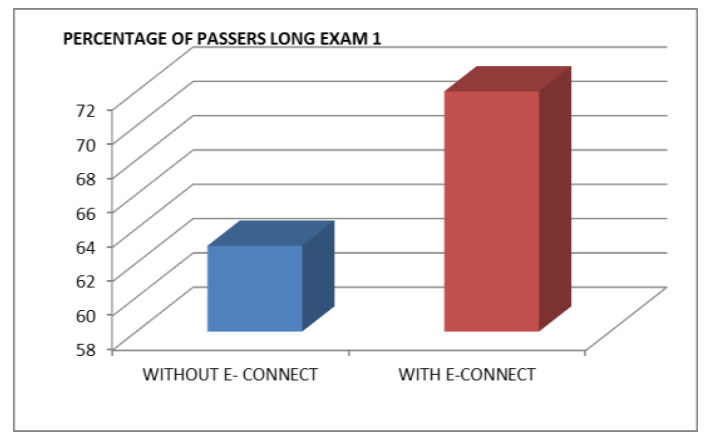

Fig. 6. Percentage of passers in long exam 1.

The percentage of passers were determine and showed that for three long exams there is an increase of $8.73 \%, 11.65 \%$ and $30.15 \%$ respectively. With the application of e-connect technology students improved in their performance which caused the increase of number of passers, as shown in Fig. 6 to Fig. 9.

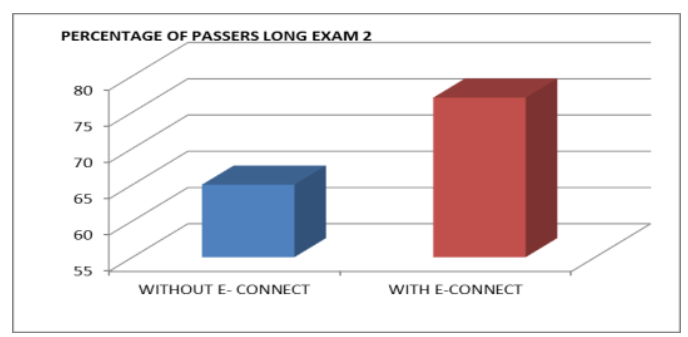

Fig. 7. Percentage of passers in long exam 2.

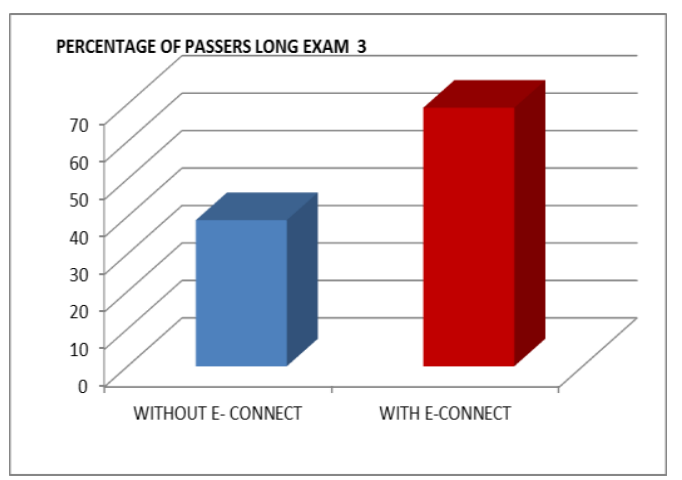

\begin{tabular}{|c|c|c|c|c|}
\hline \multirow[t]{2}{*}{$\begin{array}{l}\text { Long } \\
\text { Exam }\end{array}$} & \multicolumn{2}{|c|}{ Average Mean of Class } & \multicolumn{2}{|l|}{$\begin{array}{l}\text { Percentage } \\
\text { of Passers }\end{array}$} \\
\hline & Without & With & Without & With \\
\hline & e-connect & e-connect & e-connect & e-connect \\
\hline 1 & 59.59 & 67.01 & 63.15 & 71.88 \\
\hline 2 & 59.98 & 66.69 & 64.91 & 76.56 \\
\hline 3 & 50.12 & 63.47 & 38.60 & 68.75 \\
\hline
\end{tabular}

Fig. 8. Percentage of passers in long exam 3.

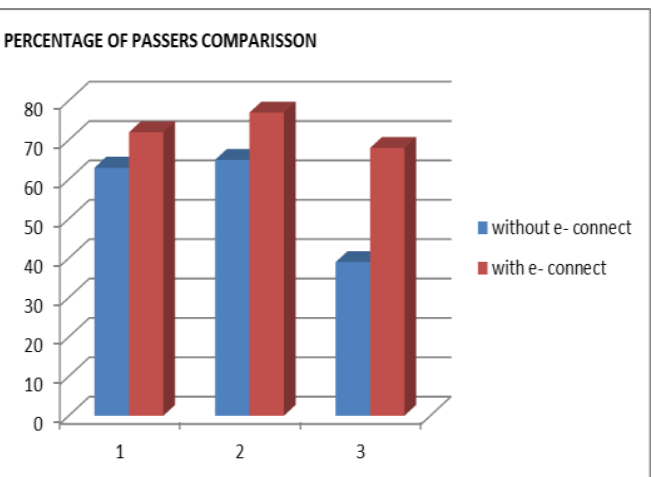

Fig. 9. Comparisons in percentage of passers in long exam

\section{Summary of Results}

Data shown below is the summary of result for the average mean and percentage of passers for the four sections who underwent the study.

\section{CONCLUSION}

The use of technology nowadays in teaching and instructions is necessary. The increased in the average mean and the number of passers in this study was manifested by the 
use of the e-connect technology because it offered much to learn about many interesting opportunities. The use of this technology is really matched with the current generation that we have. The knowledge in technology by the current generation made them adept in computer since this is where their life evolves. Almost all universities worldwide offers online learning since it offers the ability to extend their reach well beyond their location [8]. E-connect technology offer students gain learning at their own pace. They could also advance and repeat lectures through the site. From the results obtained it is clearly manifested that technology improved the performance of the students. The continuous technological advances offers a variety of learning and learning in the web-based environment caused a drastic change in one's academic performance as seen in the results. Technology is needed by the students. It shifts the stride of education and enhances the performance of the students at the same time.

\section{RECOMMENDATION}

Since the number of sections considered in this study is only four it is best to consider more sections to determine the exact effect of this technology. The e- connect technology is in existence for 1 year but the result showed already a greater impact. Therefore the use of this technology can be continued because with the improving technology it is always best to integrate computer in the learning process of a student. Different interventions can be done but should always consider the nature of the learner to easily assess what is the best intervention. The current generation which is the generation $\mathrm{Y}$ or the millennial generation can easily adapt to the emerging technology. The use of technology might not be easy for some who are not techie or who are not capable of exploring the internet. Even though they are 24/7 and 365 online tutorial should be provided to the students on how to access the internet or how to use the site. Exercises uploaded in the net for coursework should be of different level of difficulty to easily address the weakness of the students.

Computer and internet access should be provided by the schools as long as they are in the school premise for them to easily access their online courses [4].

\section{ACKNOWLEDGMENT}

The author would like to thank the Administrators of Malayan Colleges Laguna, Philippines for encouraging us to write a research paper full support. If not because of them this paper would not be published. They are Engr. Dennis H. Tablante, Dr. Joy Hofilena, Dr Liza B. Patacsil, and Mr. Aloysius Nathaniel S. Costales. Special thanks were given to her husband Joel and children (Faye, Joel Jr, Joshua and Jeremiah) and most of all to our loving God Jesus Christ.

\section{REFERENCES}

[1] Connect. All the help and support you need. [Online]. Available: http://connect.customer.mcgraw-hill.com/features/students/\#help-whe n-and-where-you-need-it-most

[2] Connect. [Online]. Available: http://connect.mcgraw-hill.com/connectweb/login/?\&BRANDING_V ARIANT_KEY=en_us_default_default\&node=connect_20

[3] Talented heads. (April 9, 2013). [Online]. Available: http://www.talentedheads.com/2013/04/09/generation-confused/

[4] E. Red, H. Borlongan, T. Briagas, and M. Mendoza. An assessment of the elearning readiness state of faculty members and students at malayan colleges laguna. [Online]. Available: www.ijcim.th.org/past_editions/2013V21N3/3.Page_20-26.pdf

[5] J. Carol, "Comparison of international accalaureate (IB) chemistry students' preferred vs actual experience with a constructivist style of learning in a moodle e-learning environment," International Journal for Lesson and Learning Studies, vol, 2, no. 2, pp. 155-167, 2013.

[6] Anonymous, "United states distance learning association; united states distance learning association releases white paper on successes and barriers to online learning," Education Letter, vol. 39, Nov. 24, 2010.

[7] M. Richard and W. Lawrence, "Opening the door to distance learning," Computers in Libraries, vol. 18, no. 5, pp. 51-55, May 1998.

[8] T. Robert, "Pros and cons of online learning - A faculty perspective," Journal of European Industrial Training, vol. 26, no. 1, pp. 24-37, 2002 .

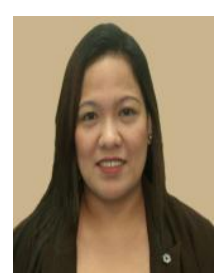

Fe G. Dampil is a member of Philippine Institute of Chemical Engineers and International Association of Computer Science and Information Technology (IACSIT). She is a licensed chemical engineer and a professional teacher. She was born on June 12, 1974 in Muntinlupa City, Philippines. She was a graduate of BS chemical engineering at Mapua Institute of Technology, Philippines (1995), and a master of engineering program in chemical engineering at the same University in 1999. She earned her certificate of teaching program in Pamantasan Ng Lunsod ng Muntinlupa, Philippines in2005. Currently, she is taking her doctor of philosophy in mathematics education in Philippine Normal University. She is now connected with Malayan Colleges Laguna teaching major courses in chemical engineering and basic courses in College of Arts and Science. 